Research Article

\title{
Environmental Scanning and Its Perception by the Managers of the Tunisian Companies
}

\author{
Raja Mejri ${ }^{1}$ and Mahmoud Zouaoui ${ }^{2}$ \\ ${ }^{1}$ Faculty of Economic Sciences and Management of Tunis, Tunisia \\ ${ }^{2}$ Higher Institute of Commerce of Tunis, Tunisia
}

Correspondence should be addressed to: Raja Mejri; rajamejri@yahoo.fr

Received 2 March 2012; Accepted 9 April 2012; Published 24 March 2013

Copyright (C) 2013 Raja Mejri and Mahmoud Zouaoui. Distributed under Creative Commons CC-BY 3.0

\begin{abstract}
Within the framework of the fast and deep change facing global economy, environmental scanning becomes a main driver for competitiveness. It's an information system directed to the outside environment of the company which plays the role of an intelligent observer who continuously seeks to supply the managers with useful information for their strategic actions. The creation of a device dedicated to this end becomes nowadays an urgent need; however it is far from being easy to realize. It is a heavy process which can only develop within the framework of a collective learning, registered in a process of knowledge management.
\end{abstract}

The survey has shown that in spite of the awareness of the importance of this practice, this activity remains punctual, unstructured, and especially related to the person of the manager who is essentially based on his own relational network.

Accustomed to quazi-monopoly of power, the manager remains unmotivated for the idea of making his subordinates participate. This would lead us to deduct that the main obstacle facing the development of this practice is cultural, related to the values and the convictions which the manager shares with his employees. Indeed, environmental scanning is primarily a state of mind and an attitude before being a means and it is up to managers to know how to mobilize the staff so that they adhere to this behaviour.

Keywords: Information - signal - environmental scanning.

\section{Introduction}

During these last years many researchers began to grant a particular attention to the information as a vital resource for the companies' strategic management. Indeed, with the fast and deep changes facing the world, the information became at the heart of the companies' competitiveness. The world henceforth belongs to the one who has a clear vision about the future and who knows how to prevent the threats and to pursue the opportunities in the right time. Environmental scanning can be defined as the set of coordinated actions of tracking, analysing, diffusing and safeguarding useful information for actors. It has for objective to increase the performance of companies through the diffusion of value-added information.

It's an intelligent listening to the early alert signals which appear in the environment and which provides continuous illumination

Cite this Article as: Raja Mejri and Mahmoud Zouaoui (2013), "Environmental Scanning and Its Perception by the Managers of the Tunisian Companies," IBIMA Business Review, Vol. 2013 (2013), Article ID 365159, DOI: $10.5171 / 2013.365159$ 
about what happens around it (KamounChouk, 2009). This behaviour does not only allow anticipating the future, it also allows a better understanding for the company's scope of activity, especially with collective interpretation of information, thing that can only improve communication between the various actors in the company (Maier \& al ., 1997).

On the basis of a literature rich with the experiences of companies and the testimonies of specialists in this domain, we will try to understand how this behaviour is perceived and practiced by managers of the Tunisian companies and what are the obstacles which can hinder its development?

In the first instance, we are going to present an overview of the literature, i.e. the interest of the behaviour of environmental scanning for the company, the concept of environmental scanning, and the mechanisms of deployment of this activity as well as the encountered obstacles. In a second step, we are going to present the methodology of the adopted research and we are going to finish by the third and the fourth parties where we are going to expose and discuss the obtained results.

\section{The Theoretical Framework of the Research}

\section{The Challenges of Environmental Scanning}

Facing the complexity and the uncertainty of the global economic framework, the companies find themselves obliged to be attentive to constant rapid changes which appear in their environment. This information system, commonly referred to as environmental scanning enables to collect the alert signals which appear in the environment which are useful for business strategic management (Delbès, 1995). The environmental scanning essentially permits to reduce the uncertainty and to be prepared for the various hazards which the company (Kamoun, 2009) might encounter. However, certain researchers think that environmental scanning contributes also to better understand the company's scope of activity and to increase security through collective interpretation of information (Maier \& al., 1997). This way of processing information will result in reducing the bias of individual interpretations which are inevitably going to contain a degree of subjectivity dictated by the cognitive preferences of the individual (Laroche \& Nioche, 1994). This behaviour therefore makes it possible to dispose useful information for taking the right decision in the convenient time, for more competitiveness (Lesca, 1992) and greater performance (Hannon, 1997).

However, over the years, the companies have focused on their internal information systems through processing operational information (financial, accounting, production, etc.) and have neglected this equally important aspect of their information system, directed to paying attention to the external environment (Lesca, 1986). But nowadays, the information became the engine of the economic life and must be carefully treated the same way as the other resources.

\section{The Concept of Environmental Scanning}

Environmental scanning is not a recent discipline. It dates from mid $19^{\text {th }}$ century with the Japanese who had very early recognized its interest. It took a whole century for the concept to appear in the Anglo-Saxon world (Romagni \& Wild, 1998). As for The Francophone, they have started to pay attention to this behaviour only at the beginning of the eighties (Delbès, 1995).

Within the framework of this work, we define environmental scanning by "the deliberate process through which the company (or a part of the latter) track and assimilates anticipatory information regarding the changes of its socio-economic environment, in order to create business opportunities, to reduce risks related to uncertainty, and to act rapidly and at the convenient time " (Lesca \& Castagnos, 2000, p. 2).

The concept of environmental scanning is a generic concept which includes various aspects: technology, competitive commercial and societal scanning, with subtle borders in the sense where there is interdependence 
between these various axes (Pateyron, 1998). However, the company does not require developing all these aspects. It may just target the part of its environment relevant to its activity.

The activities of scanning are not necessarily continuously carried out, they can be irregular or periodic (Fahey \& al., 1981), everything depends on objectives of the company, on its means and on its environment. The targeted information are mainly forward-looking information, of "weak signals", however, the word weak has no relation with their contents which can on the contrary be very rich. It is rather related to the fragmentary and disparate nature of the collected information on events which begin to emerge (Rouibah, 2001).

\section{The Implementation of Environmental Scanning Device}

Environmental scanning represents a competitive strategy for companies, whether it was big or small, especially if they are in a highly competitive environment. The creation of a device devoted to this end suddenly becomes a growing necessity. However, it is far from being an easy act. It is a long-term process which can only develop within the framework of collective learning, registered in a process of knowledge management (Lesca \& Chokron, 2002).

Several models of environmental scanning have been suggested by researchers. They wanted to present a practical knowledge which allows enlightening scanning actors within companies. All these models have as a common agreement, the adopted methodologies for information management, "an iterative process called Intelligence Assessment Cycle" (Hassid \& al., 1997 , p. 55). Nevertheless, most of the publications did not bring an actionable knowledge about the mechanisms of implementing environmental scanning device (Caron-Fasan \& Lesca, 2003).

The implementation of a unit for environmental scanning has to be made within the framework of an approach of information system project (Lesca \& Caron-
Fasan, 2008). This action imposes on the decision-makers before engaging in this action to consider the objectives to be achieved, the means to be mobilized and especially the commitment to be made by the direction (Caron-Fasan, 2003). There is no applicable universal model; everything depends on the nature of the organization, its managerial style, its capital base, the degree of staff involvement and the characteristics of the environment in which it exists.

Nevertheless, managers can choose between the centralized unit and the distributed and disseminated structure in various services of the company (Romagni \& Wild, 1998). But, when the company tries to give a greater effect to an activity, it is recommended to position it at the highest level of the hierarchy.

\section{Obstacles Facing the Implementation of Environmental Scanning}

The implementation of an internal unit for environmental scanning supposes the availability of resources and especially a managerial willingness which manages to mobilize the various actors within the company in order to integrate this behaviour in every day management. The assessment of the situation with the various observed obstacles by researchers showed that they can be classified in two categories: obstacles related to means and other related to cultural.

Concerning the first category, it is essentially related to the difficulty of the collect and analysis of environmental scanning information. Indeed, even senior executives are not used to such tasks, so how it would be for simple agents. According to Lesca \& Caron (1995), it's the first reason of disinterestedness of the employees towards this behaviour which they consider as lost and unproductive time.

There are also the financial means, which are considered by numerous managers as an obstacle. They think that that is expensive to implement an environmental scanning unit (Vergnaud, 1993), especially because its effect on the profitability is not immediate (Villain, 
1989).

We mean by the logistic tools, gathering, processing, analysing and protecting the collected data. But, contrary to what many managers think, these tools can never replace the human skills especially those of analysis and synthesis because of the special nature of the information (Lesca \& Chokron, 2002).

The second category of the obstacles is cultural, due to the stereotypes which the managers and the employees share about this behaviour. Indeed, environmental scanning is essentially a state of mind strengthened by the culture of each country, and this information sharing culture which pre-exists in certain countries like Japan or the United States is not haphazard. These countries had invested a lot of time and money for several years to reach this stage (Strap \& Ribault, 1989). In fact, individualism remains the big obstacle facing the development of environmental scanning (Hermel, 2001), as well as the problem of information retention between employees either because of power conflicts, or because of a faulty information system.

\section{The Methodological Framework of the Research}

This research suggests establishing a descriptive study of the practice of environmental scanning by the industrial Tunisian companies. We are going to focus the study on the Tunisian manager to see how does he perceive this behaviour? How he applies it? And what are the obstacles which he might encounter?

To identify the individuals who constitute our sample, we have chosen the quota method; a non-probabilistic method which allows to reproduce the same model of the relevant population through the database of the
Agency for the Promotion of Industry (API).

The number of the industrial Tunisian companies is made up of 5262 company; spread over nine (9) business sectors. We have chosen $10 \%$ of the companies from each sector, implanted in the governorate of Tunis to have 45 companies by the end.

To lead this research, we have chosen to make a quantitative research. We opted for a face-to-face survey through the administration of a questionnaire. After having contacted and fixed appointments with 45 managers chosen for their availability, we went to meet them for interviews about strategic environmental scanning. They were asked to answer closed questions, and this has made it easier for us later on to process the collected data by using the SPSS software. Nevertheless, we took advantage from this face-to-face interview to deepen certain points in relation with our subject. We point out here that the interviews lasted between 15 and 30 minutes.

\section{Results}

\section{The Perception of Environmental Scanning}

As it appears in the following table, a consensus around the importance of environmental scanning has been reached, apprehended as the main driver of the companies' strategic management. Indeed, $84.5 \%$ of the questioned companies grant a great importance to strategic importance and $93.3 \%$ of them consider it as a push for competitiveness especially within the framework of an increasing competitive economic environment. The interviewed managers are convinced that the collected data offers a better knowledge about the emerging changes in the environment, which would strengthen the decision and the action. 
Table 1: The Importance of Environmental Scanning and Its Contribution in Competitiveness

\begin{tabular}{|l|c|c|c|c|c|}
\hline & $\begin{array}{c}\text { Very } \\
\text { important }\end{array}$ & Important & $\begin{array}{c}\text { Moderately } \\
\text { important }\end{array}$ & $\begin{array}{c}\text { Not very } \\
\text { important }\end{array}$ & $\begin{array}{c}\text { Very } \\
\text { unimportant }\end{array}$ \\
\hline $\begin{array}{l}\text { The importance } \\
\text { of environmental } \\
\text { scanning }\end{array}$ & $28.9 \%$ & $55.6 \%$ & $6.7 \%$ & $4.4 \%$ & $4.4 \%$ \\
\hline & $\begin{array}{c}\text { Don't agree } \\
\text { at all }\end{array}$ & Don't agree & Neutral & Agree & $\begin{array}{c}\text { Strongly } \\
\text { Agree }\end{array}$ \\
\hline $\begin{array}{c}\text { Contribution in } \\
\text { competitiveness }\end{array}$ & $2.2 \%$ & $2.2 \%$ & $2.2 \%$ & $60 \%$ & $33.3 \%$ \\
\hline
\end{tabular}

Concerning the objectives of business intelligence behaviour, we found that $93.3 \%$ of the interviewees think that it allows a better understanding of its scope of activity and protect its market position, and even improve it. $82.2 \%$ of the interviewees asserted that environmental scanning represents a tool for the supervision of various actors of the environment and for the preparation of its responses in case of fierce competition. Similarly, $77.8 \%$ of the interviewees find that it allows finding business opportunities and $88.8 \%$ think that it helps making decisions on more solid bases. Paradoxically $84.4 \%$ of the managers don't share the opinion saying that environmental scanning allows anticipating the changes and the tendencies, although it's according to researchers the main objective of this practice, especially for companies which try to be proactive. Here we might infer a difficulty for Tunisian managers to detect and analyze environmental scanning information of weak signal type, which are recognized by their anticipatory nature.

Table 2: The Objectives of Environmental Scanning

\begin{tabular}{|l|c|c|c|c|c|}
\hline & $\begin{array}{l}\text { Strongly } \\
\text { disagree }\end{array}$ & Don't agree & Neutral & $\begin{array}{c}\text { Agree } \\
\text { Strongly } \\
\text { Agree }\end{array}$ \\
\hline $\begin{array}{l}\text { Knowing the environment and } \\
\text { reducing uncertainty. }\end{array}$ & $2.2 \%$ & $4.4 \%$ & - & $62.2 \%$ & $31.1 \%$ \\
\hline $\begin{array}{l}\text { Scanning different actors within } \\
\text { the environment. }\end{array}$ & $2.2 \%$ & $2.2 \%$ & $13.3 \%$ & $62.2 \%$ & $20 \%$ \\
\hline $\begin{array}{l}\text { Anticipate changes and } \\
\text { tendencies. }\end{array}$ & $2.2 \%$ & $15.6 \%$ & $66.7 \%$ & - & $15.6 \%$ \\
\hline $\begin{array}{l}\text { Looking for business } \\
\text { opportunities. }\end{array}$ & $2.2 \%$ & $6.7 \%$ & $13.3 \%$ & $57.8 \%$ & $20 \%$ \\
\hline Help making decisions. & $2.2 \%$ & $2.2 \%$ & $6.7 \%$ & $44.4 \%$ & $44.4 \%$ \\
\hline
\end{tabular}

The Practice of Environmental Scanning in the Tunisian Companies: Overview of the Situation

The commercial scanning is the most practiced type of environmental scanning in Tunisia. It was evoked by $91.1 \%$ of the managers. They grant it a great importance in scanning market evolution, especially the behaviour of the suppliers and the customers.
Indeed, we noticed in our interviews that the managers highlighted the importance of scanning the needs and the expectations of their clients whom they consider as the real capital of the company. Technological and competitive scanning come in the second place, respectively cited by $68.9 \%$ and $64.4 \%$ of the companies. The interest on technological scanning is greater among companies which work in sectors of rapid 
evolution such as computer science, chemistry, electronics or household electrical appliances. Competitive scanning, allows according to the managers to be constantly informed about the company's market position through watching the products offered by the competitors, the used technologies and the adopted strategies. Nevertheless, we felt that many companies make the mix between competitive intelligence and spying especially when dealing with Tunisian competitors.

Ultimately, we found that societal scanning is cited by $17.8 \%$ of companies in spite of its importance especially for the companies which are involved in international business, who need to master the political and sociocultural rules of target countries. This figure raises a little of curiosity, if we know that Tunisia has chosen for several years to be open to global economy, what obliges Tunisian entrepreneur to be constantly informed about everything that occurs outside the Tunisian borders, in particular European Union markets, which are considered to be the main economic partners of the country.

Table 3: Axes of Environmental Scanning

\begin{tabular}{|l|c|c|}
\hline \multicolumn{1}{|c|}{ Scanning-types } & Number & Percentage \\
\hline Technological scanning & 31 & $68.9 \%$ \\
\hline Competitive scanning & 29 & $64.4 \%$ \\
\hline Commercial scanning & 41 & $91.1 \%$ \\
\hline Societal scanning & 8 & $17.8 \%$ \\
\hline
\end{tabular}

In order to find out how Tunisian managers apply this practice, we wanted to know how often they monitor their environment. We have proposed three modalities: punctual, periodic and continuous scanning.

It appears from following table that environmental scanning is generally occasional. Despite the awareness of the role of this behaviour; only $31.1 \%$ of the companies continuously scan their environment, while it is periodic for $28.9 \%$ of the companies and punctual for the other 40 $\%$. We can deduce that the Tunisian manager is not yet used to be constantly on the lookout for information, which is rather driven by the need.

Table 4: Scanning Activities Frequency

\begin{tabular}{|l|c|c|}
\hline & Number & Percentage \\
\hline Punctual & 18 & $40 \%$ \\
\hline Periodic & 13 & $28.9 \%$ \\
\hline Continuous & 14 & $31.1 \%$ \\
\hline
\end{tabular}

According to the survey, the first information sources are the customers, the suppliers, the business trips and the personal relations. There are also the state structures which are considered reliable information sources and especially costless. Unfortunately the internal staff according to many managers cannot be considered an interesting source although the experiment showed that it is a very rich and that it costs nothing for the company.

Finally, to better understand the organization of environmental scanning within Tunisian companies, we asked the managers to specify whether environmental scanning is made within the framework of a permanent unit or that there are only some employees who dedicate a part of their time to track and analyze information. We also asked the interviewees to specify if this behaviour follows a strategic process, according to fixed objectives with regard to the company's needs and with a predefined budget, as it is the case with company entrepreneur in this domain.

We noticed that this activity remains poorly 
structured. Only $6.7 \%$ of the companies dispose an environmental scanning unit, they are mainly companies with a large staff beyond 50 employees. $57.8 \%$ of the companies appoint people to collect information, mainly sales executives or technicians, generally overburdened by their daily work. This lack of time according to certain managers justifies their precedence to handle this task. It will be necessary here to have a transmutation in the management style for a more participative management for the employees, because this behaviour is above all a global approach.

We had also noticed that most of the companies scan their environment randomly and in unplanned manner. Indeed, only 28.9 $\%$ of companies make targeted scanning, through choosing research axes, yet informally. Companies focus on information in direct relation with their scope of activity. There is no pre-preparation in terms of planning objectives or resource allocation, everything is punctual. Indeed, only $8.9 \%$ of the companies fix a budget for strategic scanning this activity, which they especially spend in missions and during business trips. The other managers declared that these expenses depend on the financial situation of the company.

Table 5: Environmental Scanning Organization

\begin{tabular}{|l|c|c|}
\hline & Number & Percentage \\
\hline Existence of a scanning unit & 3 & $6.7 \%$ \\
\hline Appointment of some employees & 26 & $57.8 \%$ \\
\hline Monitoring a scanning process & 13 & $28.9 \%$ \\
\hline Objectives definition & 13 & $28.9 \%$ \\
\hline Setting a budget & 4 & $8.9 \%$ \\
\hline
\end{tabular}

The Difficulties of the Implementation of an Environmental Scanning Device

We will try in this paragraph to understand the obstacles blocking environmental scanning development in the Tunisian companies.

Table 6: Environmental Scanning Obstacles

\begin{tabular}{|l|c|c|}
\hline & Number & Percentage \\
\hline Employees' lack of motivation & 31 & $68.9 \%$ \\
\hline Disinterestedness of the direction & 30 & $66.7 \%$ \\
\hline Lack of familiarity with environmental scanning & 27 & $60 \%$ \\
\hline Financial resources & 10 & $22.2 \%$ \\
\hline Lack of computing tools & 7 & $15.6 \%$ \\
\hline Difficulty of practicing environmental scanning & 6 & $13.3 \%$ \\
\hline
\end{tabular}

As it appears in the above table, the main obstacle facing environmental scanning development is related to the convictions and the ideologies which share the managers and their employees as well as the lack familiarity with this behaviour. This allows us to deduce that the problem is essentially cultural. Indeed, this behaviour was related for a long time to the person of the manager, the chief decision-maker in the company. As a result, it is to him that the task of searching for information is left to interpret in his way and to finally make the decision which seems to him adequate for the development of his company.

$68.9 \%$ of the managers believe that it is not interesting to entrust this task to their employees because of their lack of motivation. Some of them have explained to us that they tried to involve them, but the result was not encouraging, actually this saying needs to be verified. We can feel here the existence of a difficulty at the level of communication in 
Tunisian companies.

Similarly $66.7 \%$ of the managers think that it is not necessary to create an environmental scanning unit, although this does not mean creating a big team. They are convinced that the effort which they are making is widely sufficient. Yet, the existence of an environmental scanning structure in the company allows enhancing the importance of this behaviour. This allows to more easily implant this information sharing culture between the various hierarchical levels and to improve the cohesion within the company.

Equally, $60 \%$ of the managers revealed that they are not familiar with this collective environmental scanning culture, according to a methodical and strategic approach. However, many of them showed an awareness of the importance of applying this behaviour according to the set rules, so that it would be able to play its role of intelligent scanning of the environment and supporting decision-making. Certainly, environmental scanning has been over many years related to the person of the manager who got used to apply it in an individual, informal and punctual way.

Fourth, we find the financial resources cited by $22.2 \%$ of the interviewees, which would make it sure that the main obstacle is cultural.

Aside from the budget, $15.6 \%$ of the interviewees evoked the non-availability of technological tools. Yet, environmental scanning does not require sophisticated tools even if certain software allow time saving in data analysis. The most important here are the human skills.

Finally $13.3 \%$ of the interviewed managers declared that they find a difficulty in this practice, i.e. the detection and process of weak signals for the creation of relevant knowledge for decision-making. It's a figure which does not reflect enough the reality in our opinion. We think that managers do not have to take the easy way and it is may be one of the reasons behind the failure of this practice in the Tunisian companies.

\section{Discussion of the Results}

Environmental scanning becomes, more than ever before a real main driver of competitiveness for the companies which wish to remain effective. It allows companies to have the right information at the convenient time in order to make the adequate decision and not to be surprised by an increasing fierce competition.

Environmental scanning includes several types such as commercial, competitive, technological and societal which do not have the same importance. It depends on the company; its interest areas, its resources and its management information tradition.

As we have already seen, in order for scanning to properly play its role it has to be targeted, according to the needs of the company which must be defined precisely and in advance in order to channel the efforts towards a common objective and to measure afterward the impact of its activities.

A scanning device seems to be necessary. It will be responsible for gathering, processing, analysing and delivering useful information for decision-making.

This research had for objective to study how this behaviour is perceived by managers of Tunisian industrial companies, how it is practiced and what are the obstacles hindering its development.

In the first instance, the survey has shown that the managers of the Tunisian companies are aware of the importance of environmental scanning within the framework of change characterizing this new economic order.

However, this behaviour remains related to the person of the manager who mainly relies on his own relational network. $\mathrm{He}$ is accustomed to a virtual monopolization of power in his company; he does not grant a lot of confidence to his subordinates who are according to his sayings disinterested in this new practice made lose interest by this new practice in their habits.

This leads us to infer that the main obstacle facing the development of this practice is cultural, related to the values and the convictions shared by the managers and the 
employees. Indeed, environmental scanning is primarily a state of mind before being resources and it's up to the managers to know how to mobilize the staff so that they become the company's eyes and ears.

Second, we found that environmental scanning is essentially practiced to better understand the environment in which the company evolves. It is in the second place that the anticipation of changes and the tendencies comes, while it is the rationale of this behaviour. This is may reveal an uneasiness in identifying and analysing data of weak signals, thing that is expected as far as this behaviour remains relative to the person of the manager. Indeed, a single person cannot by nature have an exhaustive and clear vision of a problem because of its limited rationality.

Third, we have found that the Tunisian manager practice environmental scanning punctually, targeted to specific subjects, and often triggered by the preparation for certain projects or following crises which oblige decision-makers to strengthen their vigilance, while this behaviour should have been a continuous behaviour to better give its fruits.

Fourth, we have noticed that commercial scanning remains the most applied by managers. It is relative to market evolution scanning, essentially the behaviour of suppliers and customers. Then, we have found technological and competitive scanning. However, societal facet remains underdeveloped, which is somehow surprising in a country which made of the openness to the global economy its main economic choice.

Finally we have noticed that environmental scanning is randomly practiced in the Tunisian companies and is unstructured. There are no specialized structures to organize the whole process.

Similarly, the managers do not provide themselves with the necessary resources for its proper functioning whether human, financial or technological. This poor structuring affects the quality of collected data which requires to be analyzed before being delivered to decision-makers. The Tunisian companies which do not master the tools of methodological information are then brought to be trained for this practice in order to better perform this behaviour and to benefit from its advantages.

\section{Conclusion}

Regardless of its size or it scope of activity, the company must be constantly informed about what occurs in its environment in order to make the convenient decision at the right time. The implementation of an environmental scanning unit becomes then a necessity in order to gather, process and deliver the useful information to enlighten the decision-maker to better understand the evolution of an increasingly competitive environment.

This study has shown that in spite of the awareness of its importance, environmental scanning remains punctual, unstructured and especially related to the person of the manager who is not very motivated to the idea of engaging his employees because of their lack of motivation. Unfortunately this individualism which finds its roots in the national culture remains a major obstacle facing the development of this behaviour. Nevertheless, this study has only targeted the person of the manager, thing that did not allow us to have an accurate image of the reality of this practice in the Tunisian companies.

A further study covering the various hierarchical levels could help us to better understand this activity. Similarly, the nature of the survey, based on closed questions, with quite ready answers, would make of the collected data somehow "inferred", even if it is not deliberate. We believe that an in-depth study of some cases could have been able to outline a real profile for this practice in the Tunisian companies.

\section{References}

Caron-Fasan, M.- L. \& Lesca, H. (2003). "Implantation d'une Veille Stratégique pour le Management Stratégique: Cas d'une PME du Secteur Bancaire," La Revue des Sciences de Gestion: Direction et Gestion; $n^{\circ}$. 203, 5568. 
Delbes, R. (1995). 'La Veille Concurrentielle: Comment Peut-elle Être Stratégique?,' Revue Française du Marketing, n.155, 69-79.

Fahey, L., King, W. R. \& Nayarman, V. K. (1981). "Environmental Scanning and Forecasting in Strategic Planning: The State of the Art," Long Rang Planning, 14(1), 32-39.

Hannon, J. M. (1997). "Leveraging HRM to Enrich Competitive Intelligence," Human resource Management, 36(4), 409-422.

Hassid, L., Gustave, J. P. \& Moinet, N. (1997). 'Les PME Face au Défi de l'intelligence Économique, le Renseignement sans Complexe,' Dunod, Paris.

Kamoun-Chouk, S. (2009). "Comment Convaincre de l'utilité de la Veille Stratégique? Cas d'une PMI Tunisienne," La Revue des sciences de gestion: Direction et gestion, $\mathrm{n}^{\circ} .237-238,195-205$.

Laroche, H. \& Nioche, J. P. (1994). 'L'approche Cognitive de la Stratégie d'entreprise,' Revue Française de Gestion, ${ }^{\circ}$. 99, 64-78.

Laurent, H. (2001). 'Maîtriser et Pratiquer la Veille Stratégique,' Afnor, Paris.

Lesca, H. (1986). "Système d'information pour le Management Stratégique," Mc Graw Hill.

Lesca, H. (1992). 'Pour un Management Stratégique de l'information,' Revue Française de Gestion, n. 90, 54-63.

Lesca, H. \& Caron, M.- L. (1995). 'Veille Stratégique: Créer une Intelligence Collective au Sein de l'entreprise,' Revue Française de Gestion, $\mathrm{n}^{\circ} .105$, 58-68.
Lesca, H. \& Castagnos, J.- C. (2000). 'Signaux Faibles et Méthode Cible: Quelques Retours d'expérience,' IXème conférence de l'AIMS, Montpelier.

Lesca, H. \& Chokron, M. (2002). "Intelligence Collective Anticipative pour Dirigeants d'entreprise: Retours d'interventions," Revue Systèmes d'Information et Management, (7)4, 65-90.

Lesca, N. \& Marie-Laurence, C.- F. (2008). "Facteur d'échec et d'abondant d'un Projet de Veille Stratégique: Retours d'expérience," Revue Systèmes d'Information et Management, (13)3, 17-42.

Maier, J. L., Rainer, R. K. \& Snyder, C. A. (1997). "Environmental Scanning for Information Technology: An Empirical Investigation," Journal of Management Information Systems, (14)2, 177-200.

Martinet, B. \& Ribault, J.- M. (1989). "La Veille Technologique, Concurrentielle et Commerciale," Les Editions d'organisation.

Pateyron, E. A. (1998). 'La Veille Stratégique,' Economica.

Romagni, P. \& Wild, V. (1998). 'L'intelligence Économique au Service de la Stratégie D'entreprise,' Les presses du Management, Paris.

Rouibah, K. (2001). “Une Méthodologie pour la Gestion des Signaux Faibles de la Veille Stratégique: Illustrations par un Prototype," Revue Gestion 2000, nov -dec, 101-122.

Vergnaud Schaeffer, M.- P. (1993). "Veille de l'entreprise et Performance une Approche pour les PME- PMI," Direction et Gestion des Entreprises, $\mathrm{n}^{\circ} .143$ sept-oct, 55-67.

Villain, J. (1989). "L'entreprise aux Aguets," Masson. 